\title{
CORRESPONDENCE
}

Prevention of coronary heart disease

R W D Turner, FRCP, and K P Ball, FRCP;

J F Soothill, FRCPATH.............. 365

Preoperative radiotherapy in rectal cancer

W Duncan, FRCR, and A N Smith, FRCSED . 366

The elderly mentally ill-whose

responsibility?

J A M Gray, DPH, and J S Rodgers, MFCM. . 366

What do community physicians do?

W S Parker, FFCM.................. 367

Modified operation for ingrowing toenails

B V Palmer, FRCs, and D L Stevenson,

FRCS .......................... 367

Rebound hypertension after acute

methyldopa withdrawal

J N Scott, MB, and D G McDevitt, MD . . . . 367

Short-term recovery of mental efficiency

after anaesthesia

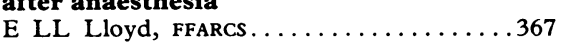

Propranolol in hypertension

J B Collinson, MRCPSYCH.

Abortion and maternal deaths

A

Out-of-hours calls in general practice

B T Williams, MD, and others..........368

Management of eclampsia

A B MacLean, MB, and others.......... 368

Fitness for diving

Surgeon Commander D H Elliott, MFCM, and

Surgeon Commander R R Pearson, MB. . . .369

Guillain-Barré syndrome

C P Petch, FRCP. . . . . . . . . . . . . 369

Diet and malignant disease

H S Smith, MA..................369

Mechanism of action of antiallergic drugs

C J Vardey, BSC, and I F Skidmore, DPHIL . . 369 Alcohol and the brain

A R Foster, MRCPSYCH. . . . . . . . . . . . 369

Death from asthma

D R Tant, MB................... 370
America-the closing door

B McGuinness, MD . . . . . . . . . . . . . . 370

Consultant contract-a reduction in work load?

A S Jackson, FFARCS................. 370

Doctors and trade unionists

M G Barley, MB; P W M Copeman, FRCP . 370

Social service delays

K C Harvey, MrCGP.............. 370

Incomes: vive la différence

J A Hicklin, MrCPED...............371

NHS superannuation and war service

M H Hughes, frCPATH.............37

Points from letters Management of acute myocardial infarction ( $\mathrm{J} \mathrm{G}$ Cooney); New look at monoamine oxidase inhibitors ( $R \mathbf{M}$ Whittington); Prevention of coronary heart disease (C H Foggitt); The geriatric ward and the patient (Kathleen Hurly); Future of the NHS (J C Nicholson) ...................
Correspondents are urged to write briefly so that readers may be offered as wide a selection of letters as possible. So many are being received that the omission of some is inevitable. Letters should be signed personally by all their authors.

\section{Prevention of coronary heart disease}

SIR,-Although we welcome the distribution by the DHSS of the report of the joint working party of the Royal College of Physicians and the British Cardiac Society on the prevention of coronary heart disease $(\mathrm{CHD})^{1}$ to all doctors, we disagree with certain points made by the Chief Medical Officer in his covering letter. We cannot accept his statement that there is only "a relatively minor difference" between the $\mathrm{RCP} / \mathrm{BCS}$ report and that of the advisory panel of the Committee on Medical Aspects of Food Policy (COMA), because in fact the differences are major, as Dr David Owen himself agreed in his recent TV discussion with Sir George Godber (Inside Medicine, BBC2, 19 July).

The most important are that COMA does not advise the partial substitution of saturated by polyunsaturated fatty acids (PUFAs) or restriction of cholesterol; the first because "in their opinion the available evidence that such a dietary alteration would reduce [the risk of the development of ischaemic heart disease] in the United Kingdom at the present time is not convincing" and the second because they had "found no evidence which relates the number of eggs consumed to a risk of ischaemic heart disease."

We understand that the parent committee considered the RCP/BCS report as one item in a single meeting and did not refer it back to their advisory panel, having decided that there was no fresh evidence to alter their original opinion. We are surprised that they did not decide to re-examine the evidence since so much had been overlooked in thei report, and more has appeared since. The conclusions of COMA ran counter not only to those of the $\mathrm{RCP} / \mathrm{BCS}$ report but to those of 11 other national or international com mittees which had at that time examined the evidence. Nor did they explain why they came to such different conclusions. This has led to a distinguished nutritionist in a highly critica editorial on $\mathrm{COMA}^{3}$ to conclude that at least the UK population would serve as a control as regards the dietary advice being offered in other countries. COMA did recommend a reduction in the consumption of saturated fat in the UK, but on this no action seems to have been taken. An inquiry to the DHSS brought the reply that "they had not been in the habit of issuing advice direct to the public, and it was a matter of conjecture as to how effective such measures would be. They relied to a great extent on publicity in professional journals." COMA in fact brought little publicity, and comment in general was unfavourable.

The decision of COMA not to recommend an increase in PUFAs on the grounds that there was no evidence that this would lower the incidence of CHD reflects the familiar attitude of "no action without proof" but ignores the fact that proof is unobtainable and that the probability of benefit is very high. In 1972 after detailed studies in the United States it was decided that dietary trials in a free-living population were not feasible, not only because of the prohibitive costs but because of the logistics. As in so many areas of medical practice decisions have to be taken on evidence that is short of proof. Reasons supporting the substitution of saturated by polyunsaturated fat include the following: (1) PUFAs reduce plasma cholestero and triglyceride and help to counter the almost unavoidable excess of saturated fats in modern diets. (2) PUFAs prevent the synergistic effect of saturated fat and carbohydrate in raising plasma triglycerides. (3) A reduction in saturated fat has to be replaced by something else, and carbohydrate, if not used for energy, is stored as saturated fat. (4) Experimentally PUFAs reduce platelet aggregation, and in a major dietary trial in man a simila effect was considered to account for a reduction in the incidence of coronary attacks. (5) PUFAs are essential for the integrity of all cell membranes, but are relatively deficient in Western diets. (6) In non-human primates a Western-type diet result in severe atherosclerosis similar to if not identical with that which occurs in man. On the other hand this was prevented in those on the "prudent" diet, with partial substitution of saturated by polyunsaturated fat and reduction in cholesterol, now being advised in so many countries. (7) Finally, most people are accustomed to taking fat, which makes food pleasanter and easier to prepare, and they would not accept a reduction of saturated fat without some substitution.

Unlike COMA, nearly every other committee has advised a reduction of dietary cholesterol. It has now been clearly established that, although there is wide individual variation, about $40 \%$ of dietary cholesterol is usually absorbed, and total absorption is in proportion to intake over the range normally consumed. The reccmmendations of the $\mathrm{RCP} / \mathrm{BCS}$ report for the population as a whole to eat fewer egg yolks is in line with nearly every other report.

In conclusion, the Government should surely now do much more than circulate the report to all practitioners. The $\mathrm{RCP} / \mathrm{BCS}$ report states: "There are considerable implications in the dietary recommendations for national food policy, for the producers and the manufacturers of food and for the regulations concerning food labelling. Nutritiona practices and catering in schools, hospitals, the armed Forces and other organisations may require to be reviewed." There are also considerable implications for all restaurants, which should be encouraged to offer a choice, and for health education on food. In these areas doctors can do little by themselves and the Government should now give a clear lead. A fresh advisory panel should be appointed to give urgent consideration to the matter and especially to the reasons why the official 
policy of the UK is out of step with the views of so many other countries.

RICHARD TURNER

University of Edinburgh

Keith BaLI

Central Middlesex Hospital,

' Joint Working Party, Fournal of the Royal College of Physicians of London, 1976, 10, 213.

2 Department of Health and Social Security, Diet and

${ }^{3}$ Den Hartog, C, Nutrition and Metabolism, 1974, 17,

193.

SIR,-Like many others, I have now received my second copy of Prevention of Coronary Heart Disease (CHD) by the joint working party of the Royal College of Physicians and the British Cardiac Society, ${ }^{1}$ this time with benediction from the Chief Medical Officer.

The law of diminishing returns applies to disease preventive campaigns involving community co-operation, so effort should be placed only where effect is likely, as in the prevention of much epidemic illness by hygiene and immunisation. In a sane society stopping smoking would have almost completely eliminated lung cancer, but the efforts at application of this firmly established relationship have been rather disappointing. Many people, however, have benefited from it, not only by prevention of lung cancer but also probably by the prevention of much other disease, including CHD, since it is the only risk factor the withdrawal of which in the general population has keen shown to reduce CHD.

Following the publication of the joint working party's report there has been a spate of publicity in the media, from which many intelligent lay people have formed the impression that we know that we can influence the incidence of $\mathrm{CHD}$ by altering the fat in our diet. Only two studies have been done on this, both quoted in the report; one produced no significant effect and the other was so badly designed that even the report recommends caution in its interpretation. To give pride of place and length to this unsubstantiated concept in the report is a distortion which was accentuated in its recommendations. The media have then greatly exaggerated this distortion. It arises from the assumption that associations are necessarily causative. Since such an assumption is insecure, it is essential that successful studies are completed demonstrating such an effect before our limited public goodwill is used up in applying it. At present our publicity in this field should concentrate on what is established-that all persons at special risk to $\mathrm{CHD}$ should stop smoking, as indeed everyone should. This is not the lesson which comes clearly from the report or from the ensuing publicity, and I feel that the joint working party is responsible for the latter as well as the former, since this effect could have been predicted.

But that does not mean that diet is irrelevant, and individual doctors may recommend this in the management of individual patients. Indeed, the whole community should change its diet, but for other, valid reasons which shed doubts on the morality of the working party's recommendations. At a time of disastrous world food shortage they say that we should avoid cream and top of the milk and cut off the fat from meat-and presumably throw it and the cream away. Every calorie of it represents at least 10 calories of edible carbohydrate in animal feed. They say that we should use nutritionally unnecessary quantities of vegetable oil, which would mainly be grown in developing countries which may be short of the really vital commodity-starch. There is no doubt that we "westernised" adults eat far more protein and fat than we need and more calories than are good for uschildren are different in their requirements. As responsible world citizens we should adopt lower-calorie, high-starch diets, with a higher proportion of our protein and fat of vegetable origin (and British farmers and agricultural researchers should learn to grow these here) and eat plenty of green vegetables to satisfy appetite. Most of us will eat some animal food, but if we keep it down to our requirements there will be no problem of animal fat if we eat the lot. Every calorie saved would save the world 10 , it would do us no harm, and might even do us some good (for example, perhaps reduce $\mathrm{CHD}$ ). Stopping smoking would do that, and would leave more land for food growing. That gets priorities into perspective -both scientific and moral.

London NW11

J F SOOTHILL

Joint Working Party, fournal of the Royal College of Physicians of London, 1976, 10, 213.

\section{Preoperative radiotherapy in rectal cancer}

SIR,-In March 1976 a trial of preoperative radiotherapy in rectal cancer was begun under the auspices of the Medical Research Council. The trial is designed to compare a two-week regimen of preoperative radiotherapy similar to that used in a US Veterans Administration trial with low-dose $x$-ray treatment given in a single exposure.

The Veterans Administration Surgical Co-operative Group trial ${ }^{1}$ published in 1973 showed that a radiation dose of about 2000 rads to the whole pelvis, delivered in 10 fractions over two weeks, significantly improved the survival of patients with Dukes stage-C tumours who were subjected to abdominoperineal resection. It was noted also that there was a statistically significant decrease in the number of patients found to have involved lymph nodes in the resected specimen in the group who received preoperative irradiation.

At the present time 12 regions in the United Kingdom are collaborating in the Medical Research Council trial and over 250 patients were admitted to it in the first year. There has been no report of operative difficulties after irradiation and the operative morbidity and mortality have been found to be the same in the control and in the two irradiated groups

We would be grateful for the courtesy of your columns to bring this trial to the attention of other surgeons and radiotherapists to whom an invitation is extended to participate. Details of the trial and copies of the protocol and proforma may be obtained by writing to us.

Department of Radiotherapy,

W DUNCAN

Department of Surgery,
Western General Hospital, Edinburgh

' Rowitt, B, et al, Radiology, 1973, 108, 389.
The elderly mentally ill - whose responsibility?

SIR,-The article by Miss Pauline Pasker and others (17 July, p 164) discusses an important issue but greatly underestimates the gravity of the situation. The authors make the same mistake as the DHSS in considering only the changes in the over- 65 population. In fact the most significant factor is the increase in the over-75s, because they use the services much more frequently than the 65-74-year-old age group. For example, in Oxfordshire they use the home help and district nursing service six times as frequently as the younger elderly.

From the Government Actuary's figures ${ }^{1}$ we can see that in the next 10 years there will be an increase of 132000 people over the age of 65 , but this hides an increase of nearly half a million people aged over 75 (table I). This is the most significant figure for looking at future services, especially for mentally ill people.

TABLE I-Estimated and projected populations of England and Wales 1975-84 (in thousands) ${ }^{1}$

\begin{tabular}{|c|c|c|c|c|}
\hline & & 1975 & 1984 & Changes \\
\hline Men & $\left\{\begin{array}{l}65-74 \\
75 \text { and over }\end{array}\right.$ & $\begin{array}{r}1922 \\
778\end{array}$ & $\begin{array}{r}1815 \\
978\end{array}$ & $\begin{array}{l}-107 \\
+200\end{array}$ \\
\hline Women & $\left\{\begin{array}{l}65-74 \\
75 \text { and over }\end{array}\right.$ & $\begin{array}{l}2551 \\
1705\end{array}$ & $\begin{array}{l}2304 \\
1991\end{array}$ & $\begin{array}{l}-247 \\
+286\end{array}$ \\
\hline
\end{tabular}

TABLE II-Mental illness hospitals and units: agespecific admission rates per 100000,1964 and $1970-4^{2}$

\begin{tabular}{l|l|l|l|l|l}
\hline & 1964 & 1970 & 1971 & 1972 & 1973 \\
\hline All admissions & 493 & 494 & 485 & 490 & 479 \\
First admissions & 258 & 188 & 178 & 172 & 167 \\
All admissions & 692 & 748 & 733 & 724 & 710 \\
First admissions & 503 & 415 & 393 & 371 & 348 \\
\hline
\end{tabular}

The hospital response to the ageing population with mental illness has been to admit fewer of them, as shown in table II. Obviously the problems are accumulating in the community and in old people's homes. There is a policy confusion in future planning for these problems. The DHSS makes its guesses from figures based on the over- 65 population and changes in the total population, the latter estimate being no more than a guess because of the rapid changes in birth rates and the former, though more accurate, underestimating the extent of the problem. The keystone of DHSS policy is that half the elderly people who are severely mentally infirm should be in the community hospitals, ${ }^{3}$ though this is resisted by the general practitioners who must take day-to-day management of these hospitals, and the Wallingford Community Hospital Research Report, on which much of the DHSS thinking is based, specifically defines "grossly confused or disturbed patients" as a group not suitable for admission. ${ }^{4}$

The key to this lies in the future policy for old people's homes, and this is a policy vacuum. The DHSS has issued a draft circular on the care of residents in old people's homes which avoids the issue of their operational policy, and they are left having to admit all the cases that can no longer be maintained in the community, but which are not suitable for hospital -a motley collection of problems.

AdAM N SMITH 